\title{
Liquid-containing Refluxes and Acid Refluxes May Be Less Frequent in the Japanese Population Than in Other Populations: Normal Values of 24- hour Esophageal Impedance and pH Monitoring
}

\author{
Osamu Kawamura, ${ }_{1}{ }^{*}$ Yukie Kohata, ${ }^{2}$ Noriyuki Kawami, ${ }^{3}$ Hiroshi lida, ${ }^{4}$ Akiyo Kawada, ${ }^{1}$ Hiroko Hosaka, ${ }^{1}$ Yasuyuki Shimoyama, \\ Shiko Kuribayashi, ${ }^{1}$ Yasuhiro Fujiwara, ${ }^{2}$ Katsuhiko Iwakiri, ${ }^{3}$ Masahiko Inamori, ${ }^{5}$ Motoyasu Kusano, ${ }^{1}$ and Micho Hongo ${ }^{6}$ \\ ${ }^{1}$ Department of Gastroenterology and Hepatology, Gunma University Hospital, Maebashi, Japan; ${ }^{2}$ Department of Gastroenterology, Osaka \\ University Graduate School of Medicine, Osaka, Japan; ${ }^{3}$ Department of Gastroenterology, Nippon Medical School, Graduate School of Medicine, \\ Tokyo, Japan; ${ }^{4}$ Department of Medical Education, Yokohama City University School of Medicine, Yokohama, Japan; ${ }^{5}$ Office of Postgraduate \\ Medical Education, Yokohama City University Hospital, Yokohama, Japan; and ${ }^{6}$ Kurokawa general hospital, Miyagi, Japan
}

\section{Background/Aims}

Twenty-four-hour esophageal impedance and pH monitoring allows detection of all types of reflux episodes and is considered the best technique for identifying gastroesophageal refluxes. However, normative data for the Japanese population are lacking. This multicenter study aimed to establish the normal range of 24-hour esophageal impedance and pH data both in the distal and the proximal esophagus in Japanese subjects.

\section{Methods}

Forty-two healthy volunteers ( 25 men and 17 women) with a mean \pm standard deviation age of $33.3 \pm 12.4$ years (range: 22-72 years) underwent a combined 24-hour esophageal impedance and pH monitoring. According to the physical and pH properties, distal or proximal esophageal reflux events were categorized.

\section{Results}

Median 45 reflux events occurred in 24 hours, and the 95th percentile was 85 events. Unlike previous reports, liquid-containing reflux events are median 25/24 hours with the 95th percentile of 62/24 hours. Acidic reflux events were median 11/24 hours with the 95th percentile of 39/24 hours. Non-acidic gas reflux events were median 15/24 hours with the 95th percentile of 39/24 hours. Proximal reflux events accounted for $80 \%$ of the total reflux events and were mainly non-acidic gas refluxes. About $19 \%$ of liquid and mixed refluxes reached the proximal esophagus.

\section{Conclusions}

Unlike previous studies, liquid-containing and acidic reflux events may be less frequent in the Japanese population. Non-acidic gas reflux events may be frequent and a cause of frequent proximal reflux events. This study provides important normative data for 24hour impedance and $\mathrm{pH}$ monitoring in both the distal and the proximal esophagus in the Japanese population.

(J Neurogastroenterol Motil 2016;22:620-629)

Key Words

24-hour esophageal impedance and pH monitoring; Gastroesophageal reflux; Japanese population; Normal values; Proximal reflux

Received: December 12, 2015 Revised: February 16, 2016 Accepted: April 9, 2016

(a) This is an Open Access article distributed under the terms of the Creative Commons Attribution Non-Commercial License (http://creativecommons. org/licenses/by-nc/4.0) which permits unrestricted non-commercial use, distribution, and reproduction in any medium, provided the original work is properly cited.

${ }^{*}$ Correspondence: Osamu Kawamura, MD, PhD Department of Gastroenterology and Hepatology, Gunma University Hospital, 3-39-25, Showa-machi, Maebashi, Gunma 3718511, Japan

Tel: +81-27-220-8137, Fax: +81-27-220-8137, E-mail: osamuk@gunma-u.ac.jp 


\section{Introduction}

Patients with gastroesophageal reflux disease (GERD) are reported to have a lower quality of life than those with mild heart failure or angina pectoris. ${ }^{1}$ The prevalence of GERD is reported to be increasing in Japan. ${ }^{2}$ This is thought to be due to adoption of a western diet and a decrease in the prevalence of Helicobacter pylori infection. Accordingly, there is a greater need to elucidate the pathophysiology of GERD in Japanese patients.

Esophageal impedance monitoring is a technique for determining the physical characteristics (liquid, gas, or mixed) of refluxate, and combining impedance monitoring with $\mathrm{pH}$ recording makes it possible to assess whether reflux is acidic or non-acidic. One study demonstrated that non-acidic reflux caused GERD symptoms in patients on proton pump inhibitor (PPI) therapy. Recent studies using this technique have found an association between symptoms and non-acidic reflux in patients with PPI-resistant GERD ${ }^{4}$ and in patients with non-erosive reflux disease (NERD). ${ }^{5}$ It has also been reported that gas or gas-containing reflux which reaches the proximal esophagus is an important cause of symptoms in GERD patients, as is pharyngeal gas reflux in patients with reflux laryngitis or chronic cough. ${ }^{6-8}$ Combined impedance and $\mathrm{pH}$ monitoring is the only method with a high sensitivity for detection of all types of reflux. ${ }^{9}$ Because this technique is becoming important for both research and clinical practice, data on the normal ranges of impedance and $\mathrm{pH}$ parameters are needed to distinguish normal from abnormal persons, ie, GERD patients. There have already been some reports of normal values determined in healthy volunteers of other countries. ${ }^{10-14}$ In a normative study from the USA, ${ }^{11}$ only liquid-containing (liquid and mixed) reflux was analyzed. In another normative study from Europe, ${ }^{12}$ gas reflux events were considered separately and were not characterized by $\mathrm{pH}$. All of studies including that from China $^{14}$ did not analyze precise physical and $\mathrm{pH}$ properties in the proximal esophageal reflux events. Moreover, there could be significant differences of normative data between the Japanese population and other populations because of differences in dietary habits or race. Although many Japanese people adopt a western diet, meals are not completely the same as in the western countries. Kawamura et $\mathrm{al}^{8}$ determined normal values for esophageal and pharyngeal reflux events in healthy Japanese volunteers in a study of patients with chronic cough, although the number of volunteers was only 10. However, in their study, the number of liquid and mixed reflux events in the distal esophagus of healthy controls were $8 \pm 2$ and $10 \pm 3$, respectively. The median and 95th percentile value of reflux events per 24 hours in the USA study ${ }^{11}$ were 30 and 75, respectively. Therefore, the number of reflux events in the Japanese population might be less frequent than those in the USA population. Accordingly, we performed a multicenter study to establish the normal ranges of 24-hour esophageal impedance and $\mathrm{pH}$ parameters in both the distal and the proximal esophagus in the Japanese population.

\section{Materials and Methods}

\section{Subjects}

Healthy volunteers were recruited from 4 university hospitals for 24-hour esophageal impedance and $\mathrm{pH}$ monitoring. They had no gastrointestinal symptoms, no history of thoracic or digestive surgery, and no medications that could alter gastric acidity or gastroesophageal motility. Subjects with $H$. pylori infection, known diseases, pregnant women, and breast-feeding women were excluded. All of the subjects underwent upper gastrointestinal endoscopy and were confirmed to have no abnormalities of the esophagus, stomach, and duodenum, as well as no hiatal hernias. We checked for $H$. pylori infection by measuring the serum level of anti- $H$. pylori IgG antibody. This study was approved by the Institutional Review Board of each hospital (approval No.777, UMIN-CTR [University hospital Medical Information Network-Clinical Trials Registry] ID: 000004064). Written informed consent was obtained from all subjects and the study was performed in conformity with the Declaration of Helsinki.

\section{Impedance and pH Monitoring}

After the subjects fasted for at least 5 hours, high-resolution esophageal manometry (Manoscan, Medtronic, Minneapolis, MN, USA) was done to exclude esophageal motility disorders according to the Chicago classification ver. $3.0^{15}$ and to identify the location of the lower esophageal sphincter (LES). Then the subjects underwent 24-hour esophageal impedance and $\mathrm{pH}$ monitoring. Impedance was recorded with a combined impedance and $\mathrm{pH}$ probe (model ZAN-BG-44; Sandhill Scientific Inc, Highlands Ranch, CO, USA), which was a polyvinyl assembly with a diameter of $2.3 \mathrm{~mm}$ containing a series of cylindrical electrodes (each $4 \mathrm{~mm}$ in axial length) at $2 \mathrm{~cm}$ intervals. The probe was connected to an ambulatory data acquisition unit (Sleuth or ZepHr; Sandhill Scientific Inc), and the sampling frequency of both impedance and $\mathrm{pH}$ data was set at $50 \mathrm{~Hz}$. Esophageal and gastric $\mathrm{pH}$ were measured with antimony $\mathrm{pH}$ electrodes. Before each study, the electrodes 
were calibrated with 2 buffer solutions ( $\mathrm{pH} 4.0$ and $\mathrm{pH}$ 7.0). After esophageal manometry, the combined impedance $/ \mathrm{pH}$ monitoring assembly was inserted nasally under topical anesthesia with $2 \% \mathrm{Xy}$ locaine jelly (AstraZeneca K.K., Osaka, Japan), and was positioned so that the $\mathrm{pH}$ electrodes were located $5 \mathrm{~cm}$ above and $10 \mathrm{~cm}$ below the LES. With the probe in this position, impedance could be measured at $3,5,7,9,15$, and $17 \mathrm{~cm}$ proximal to the upper margin of the LES. Correct positioning of the probe was confirmed by fluoroscopy. Subjects were asked to remain upright during the day and to only lie down at their usual bedtime. They were also instructed to perform their usual activities and to consume three meals during the 24-hour measurement period. Furthermore, they were instructed to press the event marker on the data recorder for meals, body position changes, and symptoms (such as heartburn, regurgitation, and belching) if any.

Just before manometry and 24-hour monitoring, each subject completed the frequency scale for the symptoms of GERD (FSSG), which is a specific questionnaire for assessing GERD that was developed in Japan. ${ }^{16}$ It consists of 12 questions: a total score of less than 8 is normal while a score equal to or above 8 indicates a diagnosis of GERD.

\section{Data Analysis}

After recording was complete, data were transferred to a personal computer for manual analysis with BioView version 5.6.3.0 software (Sandhill Scientific Inc). Data acquired at meal times were excluded from the analysis.

Changes of impedance corresponding to gastroesophageal reflux events were defined from the results of previous human studies. ${ }^{17-19}$ A liquid reflux event was identified as a decrease of impedance by $50 \%$ or more from baseline in at least the 2 distal channels that was propagated retrogradely. Gas reflux was identified as an abrupt increase of impedance by $50 \%$ or more from baseline in at least two adjacent channels with simultaneous or near-simultaneous propagation in the retrograde direction. Mixed reflux was defined as a combination of the gas reflux and liquid reflux patterns. Baseline impedance was determined as the average value during a 5 -second period immediately before the reflux event.

When esophageal $\mathrm{pH}$ recordings were assessed, acidic reflux was defined as a decrease of $\mathrm{pH}$ from above 4 to below 4 , weakly acidic reflux was defined as a decrease of more than $1 \mathrm{pH}$ unit with a nadir $\mathrm{pH}$ above 4 , and non-acidic reflux meant no change of $\mathrm{pH}$ or a decrease of less than $1 \mathrm{pH}$ unit. ${ }^{8}$ Reflux events in the proximal esophagus was stratified assuming that the acidity of refluxate in the proximal esophagus was the same as that in the distal esophagus.
Superimposed acidic reflux was also analyzed, which was defined as acidic reflux occurring before the esophageal $\mathrm{pH}$ had been restored to above 4 . All the reflux events were stratified according to its acidity and physical property.

The total acid exposure time was calculated using $\mathrm{pH}$ data. When the total distal esophageal acid exposure time, ie, the percentage of time at $\mathrm{pH}<4(\%$ time $\mathrm{pH}<4)$, exceeded $4 \%$, this was considered to be abnormal.

\section{Statistical Methods}

According to the physical and $\mathrm{pH}$ properties, distal $(5 \mathrm{~cm}$ above the upper margin of the LES) or proximal ( $15 \mathrm{~cm}$ above the LES margin) esophageal reflux events were categorized. Because reflux events did not show a normal distribution, the data are presented as the median value with the 25th, 75th, and 95th percentiles. Ninetyfifth percentile values are thought to represent the normal range. Statistical analyses of median values were performed by KruskalWallis testing followed by Dunn's pairwise multiple comparison test. The analysis of variance (ANOVA) was performed if data were normally distributed. In all analyses, $P<0.05$ was considered to indicate statistical significance.

\section{Results}

\section{Profiles of the Subjects}

Forty-five healthy volunteers were recruited. Two were excluded because of esophageal motility abnormality by high-resolution manometry (hypertensive peristalsis and weak peristalsis), and 1 was excluded due to abnormal esophageal acid exposure (\% time $\mathrm{pH}<4$ was $6.3 \%$ ). The remaining 42 healthy volunteers ( 25 men and 17 women aged $33.3 \pm 12.4$ [SD] years; range: $22-72$ years) were investigated for determination of the normal values of esophageal impedance and $\mathrm{pH}$ parameters. The mean body mass index was $21.7 \pm 2.2 \mathrm{~kg} / \mathrm{m}^{2}$. The FSSG score was determined in $28 \mathrm{sub}-$ jects and the mean total FSSG score was $2.6 \pm 0.4$ (range: 0-7).

\section{Reflux Events in the Distal Esophagus}

Monitoring was well tolerated by all of the subjects and any important technical failure did not occur. The median reflux events in 24 hours were 45 . The median acidic reflux events were 13, the median weakly acidic reflux events were 10 , and the median nonacidic reflux events were 20 (Table 1). The median reflux events in the recumbent position were 0 , and the median number of reflux events in the upright position was 43 (Table 1). Mixed reflux events 
Table 1. Gastroesophageal Reflux Events Detected by 24-hour Ambulatory Impedance and pH Monitoring in 42 Healthy Subjects

\begin{tabular}{|c|c|c|c|c|}
\hline & All reflux & Acidic reflux & Weakly acidic reflux & Non-acidic reflux \\
\hline \multicolumn{5}{|l|}{ Total } \\
\hline Median (25th, 75th) & $45(26,56)$ & $11(4,20)$ & $10(4,13)$ & $20(16,27)$ \\
\hline 95th percentile & 85 & 39 & 31 & 67 \\
\hline \multicolumn{5}{|l|}{ Upright } \\
\hline Median (25th, 75th) & $43(26,56)$ & $10(4,17)$ & $10(4,13)$ & $20(15,27)$ \\
\hline 95th percentile & 84 & 38 & 31 & 67 \\
\hline \multicolumn{5}{|l|}{ Supine } \\
\hline Median (25th, 75th) & $0(0,1)$ & $0(0,0)$ & $0(0,0))$ & $0(0,0)$ \\
\hline 95th percentile & 4 & 3 & 1 & 2 \\
\hline
\end{tabular}

Table 2. Characteristics of Gastroesophageal Reflux Determined by Ambulatory 24-hour Impedance and pH Monitoring in 42 Healthy Subjects

\begin{tabular}{|c|c|c|c|}
\hline & Liquid reflux & Mixed reflux & Gas reflux \\
\hline \multicolumn{4}{|l|}{ Total } \\
\hline Median (25th, 75th) & $9(4,13)$ & $17(7,24)$ & $17(12,24)$ \\
\hline 95th percentile & 26 & 44 & 50 \\
\hline \multicolumn{4}{|l|}{ Upright } \\
\hline Median (25th, 75th) & $8(4,13)$ & $17(7,24)$ & $17(12,24)$ \\
\hline 95th percentile & 25 & 44 & 49 \\
\hline \multicolumn{4}{|l|}{ Supine } \\
\hline Median (25th, 75th) & $0(0,0)$ & $0(0,0)$ & $0(0,0))$ \\
\hline 95th percentile & 3 & 1 & 1 \\
\hline
\end{tabular}

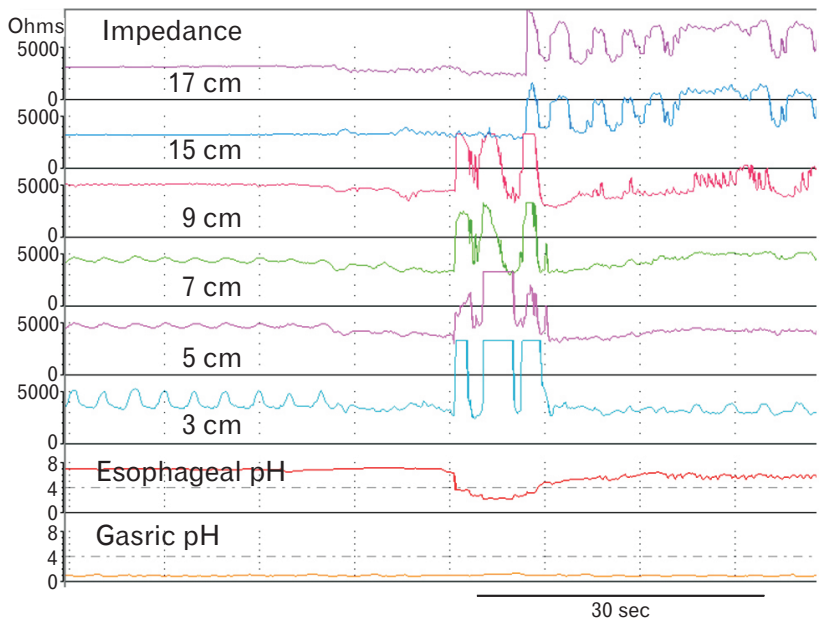

Figure 1. A representative example of acidic gas reflux. An abrupt increase of impedance was observed in the distal esophagus. At the same time, esophageal $\mathrm{pH}$ decreased below 4 . The numbers with $\mathrm{cm}$ show the distant from upper margin of the lower esophageal sphincter.
A

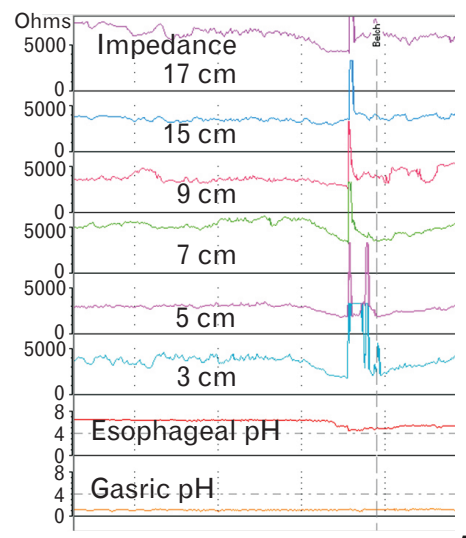

B

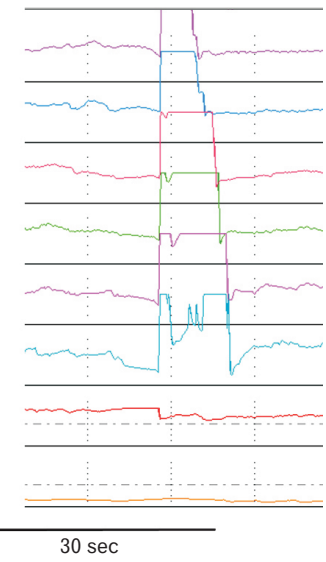

Figure 2. Representative examples of weakly acidic gas reflux. An abrupt increase of the distal and proximal esophageal impedance was observed in both $\mathrm{A}$ and $\mathrm{B}$. At the same time, esophageal $\mathrm{pH}$ decreased more than $1 \mathrm{pH}$ unit with a nadir $\mathrm{pH}$ above 4 in both examples. In A, subject pressed the event marker of belch immediately after the reflux event. The numbers with $\mathrm{cm}$ show the distant from upper margin of the lower esophageal sphincter. 
(median: 17 [39.5\%]) and gas reflux events (median: 17 [39.5\%]) were more frequent than liquid reflux events (median: 9 [20.9\%]) (Table 2). The number of liquid-containing (liquid and mixed) reflux events was 25. Acidic gas reflux events were observed in the distal esophagus in 6 subjects (median: 2, range: 1-6; Fig. 1) and weakly acidic gas reflux events occurred in 19 subjects (median: 3, range: $1-17$; Fig. 2). Superimposed acidic reflux was rare, and was only observed once each in 2 subjects while they were in the upright position.

\section{Reflux Events in the Proximal Esophagus}

As shown in Table 3, 80\% (median: 36) of reflux events reached the proximal esophagus. Table 3 also shows the number of reflux events stratified according to acidity in the proximal esophagus. Non-acidic reflux was more frequent than acidic and weakly acidic reflux combined. Reflux events in the proximal esophagus were predominantly gas reflux and the other types of reflux were uncommon (Table 4). In this analysis, almost all gas reflux events that entered the distal esophagus subsequently reached the proximal esophagus (median: 18 [25th, 75th, and 95th percentiles: 10, $24,52])$ and around half of the mixed reflux events in the distal esophagus became gas reflux in the proximal esophagus $(10[3,21$, 42]). Accordingly, the number of gas reflux events was higher in the proximal esophagus than in the distal esophagus (median: 26 vs 17). Compared with gas reflux, mixed reflux and liquid reflux were less likely to reach the proximal esophagus, with only around $18 \%$ of mixed reflux events and $20 \%$ of liquid reflux events reaching the proximal esophagus. The median number of liquid and mixed reflux events was only 5 (95th percentile 26, $19 \%$ of those in the distal esophagus).

\section{The Physical and pH Properties of Reflux Events in the Distal and Proximal Esophagus}

In the distal esophagus, acidic reflux events were mainly liquid-

Table 3. Gastroesophageal Reflux Events in the Proximal Esophagus Detected by 24-hour Ambulatory Impedance and $\mathrm{pH}$ Monitoring in 42 Healthy Subjects

\begin{tabular}{|c|c|c|c|c|}
\hline & All reflux & Acidic reflux & Weakly acidic reflux & Non-acidic reflux \\
\hline \multicolumn{5}{|l|}{ Total } \\
\hline Median (25th, 75th) & $36(23,45)$ & $7(3,13)$ & $8(3,11)$ & $17(13,24)$ \\
\hline 95th percentile & 73 & 34 & 25 & 56 \\
\hline \multicolumn{5}{|l|}{ Upright } \\
\hline Median (25th, 75th) & $35(23,44)$ & $7(3,13)$ & $8(3,11)$ & $17(13,24)$ \\
\hline 95th percentile & 73 & 34 & 25 & 56 \\
\hline \multicolumn{5}{|l|}{ Supine } \\
\hline Median (25th, 75th) & $0(0,0)$ & $0(0,0)$ & $0(0,0))$ & $0(0,0)$ \\
\hline 95th percentile & 3 & 1 & 0 & 1 \\
\hline
\end{tabular}

The proximal esophagus was defined as $15 \mathrm{~cm}$ above the lower esophageal sphincter.

Table 4. Characteristics of Gastroesophageal Reflux Events in the Proximal Esophagus Determined by Ambulatory 24-hour Impedance and pH Monitoring in 42 Healthy Subjects

\begin{tabular}{|c|c|c|c|}
\hline & Liquid reflux & Mixed reflux & Gas reflux \\
\hline \multicolumn{4}{|l|}{ Total } \\
\hline Median (25th, 75th) & $2(0,4)$ & $3(0,9)$ & $26(15,39)$ \\
\hline 95th percentile & 12 & 19 & 65 \\
\hline \multicolumn{4}{|l|}{ Upright } \\
\hline Median (25th, 75th) & $2(0,3)$ & $1(0,6)$ & $26(14,39)$ \\
\hline 95th percentile & 12 & 12 & 65 \\
\hline \multicolumn{4}{|l|}{ Supine } \\
\hline Median (25th, 75th) & $0(0,0)$ & $0(0,0)$ & $0(0,0)$ \\
\hline 95th percentile & 0 & 0 & 2 \\
\hline
\end{tabular}

The proximal esophagus was defined as $15 \mathrm{~cm}$ above the lower esophageal sphincter. 
Table 5. Gastroesophageal Reflux Events in the Distal Esophagus Stratified by Physical Properties and pH

\begin{tabular}{|c|c|c|c|c|}
\hline & All reflux & Acidic & Weakly acidic & Non-acidic reflux \\
\hline \multicolumn{5}{|l|}{ Total } \\
\hline Median (25th, 75th) & $45(26,56)$ & $11(4,20)$ & $10(4,13)$ & $20(16,27)$ \\
\hline 95th percentile & 85 & 39 & 31 & 67 \\
\hline \multicolumn{5}{|l|}{ Liquid } \\
\hline Median (25th, 75th) & $9(4,13)$ & $2(0,5)$ & $1(0,3)$ & $2(1,6)$ \\
\hline 95th percentile & 26 & 12 & 9 & 14 \\
\hline \multicolumn{5}{|l|}{ Mixed } \\
\hline Median (25th, 75th) & $17(7,24)$ & $7(2,12)$ & $3(0,6)$ & $3(2,5)$ \\
\hline 95th percentile & 44 & 31 & 19 & 18 \\
\hline \multicolumn{5}{|l|}{ Gas } \\
\hline Median (25th, 75th) & $17(12,24)$ & $0(0,0)$ & $3(0,6)$ & $15(9,21)$ \\
\hline 95th percentile & 50 & 4 & 14 & 39 \\
\hline
\end{tabular}

Table 6. Gastroesophageal Reflux Events in the Proximal Esophagus Stratified by Physical Properties and pH

\begin{tabular}{|c|c|c|c|c|}
\hline & All reflux & Acidic reflux & Weakly acidic & Non-acidic reflux \\
\hline \multicolumn{5}{|l|}{ Total } \\
\hline Median (25th, 75th) & $36(23,45)$ & $7(3,13)$ & $8(3,11)$ & $17(13,24)$ \\
\hline 95th percentile & 73 & 34 & 25 & 56 \\
\hline \multicolumn{5}{|l|}{ Liquid } \\
\hline Median (25th, 75th) & $2(0,4)$ & $0(0,2)$ & $0(0,1)$ & $0(0,1)$ \\
\hline 95th percentile & 12 & 5 & 3 & 5 \\
\hline \multicolumn{5}{|l|}{ Mixed } \\
\hline Median (25th, 75th) & $3(0,9)$ & $1(0,6)$ & $0(0,2)$ & $0(0,1)$ \\
\hline 95th percentile & 19 & 12 & 5 & 6 \\
\hline \multicolumn{5}{|l|}{ Gas } \\
\hline Median (25th, 75th) & $26(15,39)$ & $3(1,7)$ & $5(1,9)$ & $16(9,24)$ \\
\hline 95th percentile & 65 & 25 & 22 & 44 \\
\hline
\end{tabular}

The proximal esophagus was defined as $15 \mathrm{~cm}$ above the lower esophageal sphincter.

containing reflux (pure liquid and mixed), while non-acidic reflux events were mainly gas reflux (Table 5). In the proximal esophagus, acidic reflux events were mainly gas reflux (Table 6).

\section{pH Findings in the Distal Esophagus}

The median $\%$ time with $\mathrm{pH}<4$ over 24 hours was $0.3 \%$ (25th, 75th, and 95th percentiles: $0.1,0.9,3.3$, range: $0-3.7 \%$ ), while the median $\%$ time with $\mathrm{pH}<4$ in the upright position was $0.4 \%(0.1,1.2,4.4)$ and that in the recumbent position was $0 \%(0,0$, $2.3)$.

\section{Effects of Gender}

The mean age of the male subjects was $33.9 \pm 13.3(\mathrm{SD})$ years (range: 22-72) and that of the female subjects was $32.4 \pm 11.4$ years (range: 22-60), with no significant difference between genders
$(P=0.719)$. Body mass index was significantly higher in male $(22.3$ $\left.\pm 2.3 \mathrm{~kg} / \mathrm{m}^{2}\right)$ than in women $\left(20.8 \pm 1.9 \mathrm{~kg} / \mathrm{m}^{2}\right)(P=0.03)$. Total acid reflux, total acid liquid reflux, total mixed reflux and total acidic mixed reflux events were significantly more frequent in men than in women, and total mixed reflux and weakly acid mixed reflux events in the proximal esophagus were also significantly more frequent in men than in women. The acid exposure time over 24 hours was also significantly longer in men $(0.400 \%$ vs $0.200 \%)$ (Table 7$)$.

\section{Discussion}

Twenty-four hour esophageal impedance and $\mathrm{pH}$ monitoring allows detection of all types of reflux episodes ${ }^{8}$ and is considered to be the best technique to detect reflux and assess the pathophysiology of GERD. Ambulatory impedance and $\mathrm{pH}$ monitoring devices 
Table 7. Characteristics of Gastroesophageal Reflux Events Stratified by Gender

\begin{tabular}{lccc}
\hline & Males $(\mathrm{n}=25)$ & Females (n= 17) & $P$-value \\
\hline Total reflux (n) & $45(39-67-106)$ & $42(24-53-82)$ & 0.078 \\
Total acidic reflux (n) & $13(5-21-44)$ & $5(1-13-39)$ & 0.035 \\
Total weakly acidic reflux (n) & $10(8-14-27)$ & $7(2-15-31)$ & 0.182 \\
Total non-acidic reflux (n) & $19(16-28-76)$ & $23(16-28-37)$ & 0.847 \\
Total liquid reflux (n) & $9(3-15-30)$ & $7(4-10-16)$ & 0.153 \\
Total acidic liquid reflux (n) & $3(1-7-13)$ & $1(0-3-7)$ & 0.041 \\
Total mixed reflux (n) & $22(10-25-43)$ & $9(3-22-49)$ & 0.045 \\
Total acidic mixed reflux (n) & $10(4-16-31)$ & $3(1-9-32)$ & 0.033 \\
Total gas reflux (n) & $16(12-29-53)$ & $19(15-23-31)$ & 0.617 \\
Proximal reflux (n) & $38(29-56-89)$ & $1(0-6-9)$ & 0.118 \\
Proximal mixed reflux (n) & $6(2-13-26)$ & $0(0-1-4)$ & 0.021 \\
Proximal weakly acidic mixed reflux (n) & $1(0-3-7)$ & $0.200(0.005-0.400-2.100)$ & 0.016 \\
Acid exposure time (\%) & $0.400(0.100-1.400-3.600)$ & 0.037 \\
\hline
\end{tabular}

Data are shown as the median (25th-75th-95 th percentiles).

Table 8. Comparison of the Esophageal Reflux Events and \% Acid Exposure Time During 24-hour Impedance and pH Monitoring Among Different Countries

\begin{tabular}{|c|c|c|c|c|c|c|c|c|c|}
\hline \multirow[t]{2}{*}{ Location } & \multirow[t]{2}{*}{ Report } & All & Acidic & $\begin{array}{l}\text { Weakly } \\
\text { acidic }\end{array}$ & Non-acidic & Liquid & Mixed & Gas & $\begin{array}{l}\% \text { time } \\
\mathrm{pH}<4\end{array}$ \\
\hline & & \multicolumn{8}{|c|}{ (median, 95th) } \\
\hline \multirow[t]{4}{*}{ Distal } & Our study, Japan & 45,85 & 11,39 & 10,31 & 20,67 & 9,26 & 17,44 & 17,50 & $0.3,3.3$ \\
\hline & $\mathrm{USA}^{11}$ & 30,73 & 18,55 & NA & 9,26 & NA & NA & NA & $1.2,6.3$ \\
\hline & Belgium-France ${ }^{12}$ & 44,75 & 22,50 & $\mathrm{NA}$ & 11,33 & 20,55 & 17,42 & 10,30 & $0.9,3.7$ \\
\hline & China $^{14}$ & 40,75 & 22,54 & $\mathrm{NA}$ & 16,40 & 12,46 & 22,44 & 4,11 & $0.4,1.2$ \\
\hline Proximal & Our study, Japan & 36,73 & 7,34 & 8,25 & 17,56 & 2,12 & 3,19 & 26,65 & - \\
\hline
\end{tabular}

In our study, weakly acidic reflux was defined as reflux causing a decrease of more than $1 \mathrm{pH}$ unit with a nadir $\mathrm{pH}$ above 4 , while non-acidic reflux caused no change of $\mathrm{pH}$ or a decrease of less than $1 \mathrm{pH}$ unit. In other studies, non-acidic reflux was defined as reflux with a nadir $\mathrm{pH}$ between 4 and 7 . The 95 th values represent the normal range.

are approved and are now widely used in Japan, so that there is an urgent need to establish normal data for the Japanese population.

We detected a median of 45 reflux events in 24 hours, and the 95th percentile for events was 85 . Table 8 shows comparison of the number of the esophageal reflux events during 24-hour impedance and $\mathrm{pH}$ monitoring among different countries. The corresponding numbers reported by Shay et al, ${ }^{11}$ Zerbib et al, ${ }^{12}$ and Xiao et $\mathrm{al}^{14}$ were 30 and 73, 44 and 75, and 40 and 75, respectively, and did not differ much from our results. In our study, the median number of liquid, mixed, and gas reflux events were 9, 17, and 17, respectively, while the corresponding numbers reported by Zerbib et $\mathrm{al}^{12}$ and Xiao et $\mathrm{al}^{14}$ were 20,17 , and 10 , and 12,22 , and 4 , respectively. The number of liquid-containing reflux (median 25, 95th 62) and acidic reflux (median 10, 95th 31) may be less frequent in Japanese subjects than in those of other countries. These results might be due to difference in diet, race or physique. Although many Japanese people adopt a western diet, meals are not completely the same as in western countries. Fat intake in the Japanese population is far smaller than in western countries.

In contrast to liquid-containing reflux, the gas reflux events were more frequent in our study, and that is why our median number of total reflux events was higher than other authors. Balaji et al ${ }^{10}$ reported that $26.7 \%$ of all events were gas reflux events and $65 \%$ of all events were non-acidic reflux (using the same definition of nonacidic reflux as ours). In addition, Zentilin et $\mathrm{al}^{13}$ found that gas reflux events accounted for $29 \%$ of all reflux events. In our study, about $40 \%$ of events were gas reflux, and larger percentage of the gas reflux events in our study is more similar to these two reports than other reports. One explanation for the difference from the findings of other reports ${ }^{12,14}$ is that our definition of gas reflux was 
relatively less strict. In the other studies, gas reflux was defined as a simultaneous increase in impedance of $>3000 \mathrm{Ohms}$ in any 2 consecutive impedance channels with 1 channel having an absolute impedance $>7000 \mathrm{Ohms}$ (or $5000 \mathrm{Ohms}$ ). In contrast, our definition was an abrupt increase of impedance by $50 \%$ or more from baseline in at least 2 adjacent channels with simultaneous or nearsimultaneous propagation in the retrograde direction and an actual impedance value was not specified. If the criteria of other studies are adopted, apparent gas reflux events with a belch event marker often cannot be categorized as gas reflux. Also, the sensitivity of automated analysis with BioView software for detection of gas reflux is rather low and it is possible that investigators in previous studies ${ }^{11-14}$ missed a number of gas reflux events. Gas reflux events are thought to play an important role in several situations. ${ }^{6-9}$ Bredenoord et al ${ }^{6}$ reported that symptomatic pure gas reflux was more frequently accompanied by a $\mathrm{pH}$ drop (corresponding to our categories of acidic and weakly acidic reflux) than asymptomatic gas reflux in patients with suspected GERD. Therefore, it may be important to detect gas reflux events as completely as possible. Moreover, we observed acidic gas reflux in the distal esophagus of 6 subjects and weakly acidic gas reflux in 19 subjects (Fig. 1 and 2). Such acid-containing gas reflux may cause symptoms in the patients, so we cannot neglect gas reflux events. Zerbib et al $^{12}$ considered gas reflux events without liquid separately in their study and did not characterize them by $\mathrm{pH}$, but gas reflux events should be analyzed and characterized by $\mathrm{pH}$.

In our volunteers, the median $\%$ time $\mathrm{pH}<4$ over 24 hours was $0.3 \%$, confirming that they were normal. The upper limit of 24-hour esophageal acid exposure in our volunteers was 3.7\%, which corresponds to the normal values obtained by traditional 24hour $\mathrm{pH}$ monitoring. ${ }^{20}$ The corresponding values reported by Shay et al, ${ }^{11}$ Zerbib et al, ${ }^{12}$ Zentilin et al, ${ }^{13}$ and Xiao et al, ${ }^{14}$ were $1.2 \%$, $0.9 \%, 0.5 \%$, and $0.4 \%$, respectively. This suggests that the acid exposure time may be shorter in eastern than western populations. It was reported that gastric acid secretion has increased over the past 20 years in Japanese subjects, however, gastric acid secretion is still lower in Japanese subjects than in Europeans or Americans, which may be one reason for lower esophageal acid exposure and smaller number of acidic reflux events in the present study. ${ }^{21}$

In this study, weakly acidic reflux was defined as a decrease of more than $1 \mathrm{pH}$ unit with the nadir $\mathrm{pH}$ remaining above 4 , while non-acidic reflux was defined as no change of $\mathrm{pH}$ or a decrease of less than $1 \mathrm{pH}$ unit. Because Sifrim et $\mathrm{al}^{22}$ reported the importance of weakly acidic reflux (using the same definition as ours) in patients with suspected GERD, we defineded weakly acidic refluxes separately from non-acidic refluxes. In other studies of normative data ${ }^{12-14}$ weakly acidic reflux was defined as reflux events with an esophageal $\mathrm{pH}$ between 4 and 7, which corresponds to weakly acidic plus non-acidic reflux in our study. In our study, the median number of acidic reflux events and median number of weakly acidic plus non-acidic events over 24 hours was 11 and 30, respectively, while Shay et al, ${ }^{11}$ Zerbib et al ${ }^{12}$ and Xiao et al ${ }^{14}$ reported that these numbers were 18 and 9,22 and 11 , and 22 and 16, respectively (Table 8 ). Thus, acidic reflux events may be less frequent, and weakly acidic plus non-acidic events may be more frequent in our study than in the other studies. Table 5 shows that non-acidic reflux was mainly gaseous, while acidic reflux was generally liquidcontaining reflux (liquid and mixed reflux), so the reason for the higher number of non-acidic reflux events in the present study is the higher frequency or detection of gas reflux. Our results are in agreement with those of Balaji et al, ${ }^{10}$ who reported that $59 \%$ of reflux events were non-conventional acidic reflux and $58 \%$ were gas reflux. We found that $75 \%$ of all reflux events were weakly acidic plus non-acidic reflux, which would have not been detected by $\mathrm{pH}$ monitoring alone.

In this study, $80 \%$ (36 $[23,45,73])$ of reflux events reached the proximal esophagus (15 $\mathrm{cm}$ above the LES). According to Shay et al, ${ }^{11}$ Zerbib et al, ${ }^{12}$ and Xiao et al, ${ }^{14}$ the percentage of events reaching the proximal esophagus was $34 \%, 22 \%$, and $27 \%$, respectively, and these numbers are far lower than our results. This difference can also be explained by the higher number of gas reflux events reaching the proximal esophagus in our study. Because the majority of gas reflux events (87.6\%) are reported to reach the proximal esophagus, ${ }^{6}$ the number of proximal gas reflux events should increase when gas reflux is frequent in the distal esophagus. Moreover, almost half of mixed reflux events in the distal esophagus became gas reflux in the proximal esophagus, ${ }^{7,8}$ so the number of proximal gas reflux events was higher than that of distal events. In our study, the median number of acidic reflux events and the median number of weakly acidic plus non-acidic events in the proximal esophagus was 7 and 25, respectively, while Xiao et $\mathrm{al}^{14}$ found 6 and 2 events, respectively. We found that non-acidic reflux events in the proximal esophagus were mainly gas reflux events, as was the case in the distal esophagus. The previous studies of normal impedance values ${ }^{10-14}$ did not describe the physical and $\mathrm{pH}$ properties of reflux events in the proximal esophagus, and our study is the first to provide data about the properties of proximal esophageal reflux in a normal population. The median number of proximal liquid plus mixed reflux events was only 5 (95th percentile 26) and accounted for about $19 \%$ of distal liquid plus mixed reflux events, so only a 
few liquid-containing reflux events reached the proximal esophagus in Japanese normal subjects.

The chief limitation of this study was the relatively small number of subjects. The studies of Shay et al, ${ }^{11}$ Zerbib et al, ${ }^{12}$ and Xiao et $\mathrm{al}^{14}$ investigated 60,72 , and 70 subjects, respectively. In addition, Balaji et $\mathrm{al}^{10}$ and Zentilin et $\mathrm{al}^{13}$ studied 25 and 17 subjects, respectively, although they used a standard meal. When a standard meal is used, the deviation of data is decreased, but the findings will not have wide applicability because the same standard meal is not always available in clinical practice. Standard meals should be used in clinical research, but cannot always be applicable in clinical practice. Moreover, in the patients study, we believe that the assessment of reflux events after their usual meal is important. Therefore, we did not use a standard meal. Our results were comparable to those obtained in other studies, except for a higher frequency of nonacidic gas reflux. Therefore, the data that we obtained should be applicable as normal values for the Japanese population.

In conclusion, this study detected median 45 reflux events in 24 hours (the 95th percentile was 85) in healthy Japanese subjects. Unlike previous studies, liquid-containing and acidic reflux events may be less frequent which might be due to the difference in diet, race or physique, and non-acidic gas reflux events may be frequent which might be due to the difference in the analysis. We found that $80 \%$ of all reflux events reached the proximal esophagus $(15 \mathrm{~cm}$ above the LES) and these events were mainly non-acidic gas reflux. However, only $19 \%(5,26)$ of liquid and mixed refluxes reached the proximal esophagus. Reflux events were significantly more frequent in men than in women. This study provides important normative data for 24-hour impedance and $\mathrm{pH}$ monitoring in the Japanese population.

Acknowledgements: We thank all of the members of IPS (Impedance Study) research committee.

\section{Financial support: None.}

\section{Conflicts of interest: None.}

Author contributions: Osamu Kawamura: planning and conducting the study, collecting and interpreting data, and drafting the manuscript; Yukie Kohata, Noriyuki Kawami, Hiroshi Iida, Akiyo Kawada, Hiroko Hosaka, Yasuyuki Shimoyama, and Shiko Kuribayashi: collecting data; Yasuhiro Fujiwara, Katsuhiko Iwakiri, Masahiko Inamori, and Motoyasu Kusano: planning and conducting the study; and Micho Hongo: interpreting data and drafting the manuscript.

\section{References}

1. Dimenäs E, Carlsson G, Glise H, Israelsson B, Wiklund I. Relevance of norm values as part of the documentation of quality of life instruments for use in upper gastrointestinal disease. Scand J Gastroenterol 1996;31(sup$\mathrm{pl} 221): 8-13$.

2. Fujiwara Y, Arakawa T. Epidemiology and clinical characteristics of GERD in the Japanese population. J Gastroenterol 2009;44:518-534.

3. Vela MF, Camacho-Lobato L, Srinivasan R, Tutuian R, Katz PO, Castell DO. Simultaneous intraesophageal impedance and $\mathrm{pH}$ measurement of acid and nonacid gastroesophageal reflux: effect of omeprazole. Gastroenterology 2001;120:1599-1606.

4. Mainie I, Tutuian R, Shay S, et al. Acid and non-acid reflux in patients with persistent symptoms despite acid suppressive therapy: a multicentre study using combined ambulatory impedance-pH monitoring. Gut 2006;55:1398-1402.

5. Savarino E, Zentilin P, Tutuian R, et al. The role of nonacid reflux in NERD: lessons learned from impedance-pH monitoring in 150 patients off therapy. Am J Gastroenterol 2008;103:2685-2693.

6. Bredenoord AJ, Weusten BL, Curvers WL, Timmer R, Smout AJ. Determinants of perception of heartburn and regurgitation. Gut 2006;55: 313-318.

7. Kawamura O, Aslam M, Rittmann T, Hofmann C, Shaker R. Physical and $\mathrm{pH}$ properties of gastroesophagopharyngeal refluxate: a 24-hour simultaneous ambulatory impedance and $\mathrm{pH}$ monitoring study. Am J Gastroenterol 2004;99:1000-1010.

8. Kawamura O, Shimoyama Y, Hosaka H, et al. Increase of weakly acidic gas esophagopharyngeal reflux (EPR) and swallowing-induced acidic/ weakly acidic EPR in patients with chronic cough responding to proton pump inhibitors. Neurogastroenterol Motil 2011;23:411-418, e172.

9. Sifrim D, Castell D, Dent J, Kahrilas PJ. Gastro-oesophageal reflux monitoring: review and consensus report on detection and definitions of acid, non-acid, and gas reflux. Gut 2004;53:1024-1031.

10. Balaji NS, Blom D, DeMeester TR, Peters JH. Redefining gastroesophageal reflux (GER). Surg Endosc 2003;17:1380-1385.

11. Shay S, Tutuian R, Sifrim D, et al. Twenty-four hour ambulatory simultaneous impedance and $\mathrm{pH}$ monitoring: a multicenter report of normal values from 60 healthy volunteers. Am J Gastroenterol 2004;99:10371043

12. Zerbib F, des Varannes SB, Roman S, et al. Normal values and day-today variability of 24-h ambulatory oesophageal impedance-pH monitoring in a Belgian-French cohort of healthy subjects. Aliment Pharmacol Ther 2005;22:1011-1021.

13. Zentilin P, Iiritano E, Dulbecco P, et al. Normal values of 24-h ambulatory intraluminal impedance combined with $\mathrm{pH}$-metry in subjects eating a Mediterranean diet. Dig Liver Dis 2006;38:226-232.

14. Xiao YL, Lin JK, Cheung TK, et al. Normal values of 24-hour combined esophageal multichannel intraluminal impedance and $\mathrm{pH}$ monitoring in the Chinese population. Digestion 2009;79:109-114.

15. Kahrilas PJ, Bredenoord AJ, Fox M, et al. The Chicago Classifica- 
tion of esophageal motility disorders, v3.0. Neurogastroenterol Motil 2015;27:160-174.

16. Kusano M, Shimoyama Y, Sugimoto S, et al. Development and evaluation of FSSG: frequency scale for the symptoms of GERD. J Gastroenterol 2004;39:888-891.

17. Silny J. Intraluminal multiple electric impedance procedure for measurement of gastrointestinal motility. Neurogastroenterol Motil 1991;3:151162 .

18. Silny J, Knigge KP, Fass J, Rau G, Matern S, Schumpelick V. Verification of the intraluminal multiple electrical impedance measurement for the recording of gastrointestinal motility. Neurogastroenterol Motil 1993;5:107-122.
19. Fass J, Silny J, Braun J, et al. Measuring esophageal motility with a new intraluminal impedance device. First clinical results in reflux patients. Scand J Gastroenterol 1994;29:693-702.

20. Mattox HE 3rd, Richter JE. Prolonged ambulatory esophageal $\mathrm{pH}$ monitoring in the evaluation of gastroesophageal reflux disease. Am J Med 1990;89:345-356.

21. Kinoshita Y, Kawanami C, Kishi K, Nakata H, Seino Y, Chiba T. Helicobacter pylori independent chronological change in gastric acid secretion in the Japanese. Gut 1997;41:452-458.

22. Sifrim D, Dupont L, Blondeau K, Zhang X, Tack J, Janssens J. Weakly acidic reflux in patients with chronic unexplained cough during 24 hour pressure, pH, and impedance monitoring. Gut 2005;54:449-454. 